This article was downloaded by: [National Taiwan University]

On: 14 April 2009

Access details: Access Details: [subscription number 908033515]

Publisher Taylor \& Francis

Informa Ltd Registered in England and Wales Registered Number: 1072954 Registered office: Mortimer House, 37-41 Mortimer Street, London W1T 3JH, UK

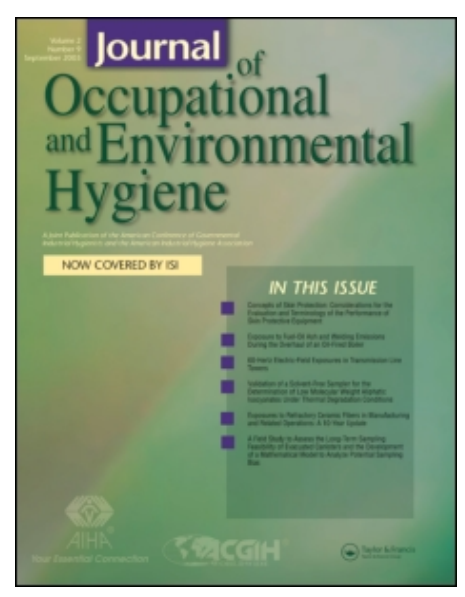

Journal of Occupational and Environmental Hygiene
Publication details, including instructions for authors and subscription information:

http://oeh.informaworld.com/soeh/title content=t713657996

\title{
Correlation Between Airflow Patterns and Performance of a Laboratory Fume Hood
}

Li-Ching Tseng a; Rong Fung Huang b; Chih-Chieh Chen a; C. -P. Chang ${ }^{c}$

a Institute of Occupational Medicine and Industrial Hygiene, National Taiwan University, Taipei, Taiwan ${ }^{b}$ Department of Mechanical Engineering, National Taiwan University of Science and Technology, Taipei,

Taiwan ${ }^{\circ}$ Institute of Occupational Safety and Health, Council of Labor Affairs, Sijhih City, Taiwan

First Published on: 01 December 2006

To cite this Article Tseng, Li-Ching, Huang, Rong Fung, Chen, Chih-Chieh and Chang, C. -P.(2006)'Correlation Between Airflow Patterns and Performance of a Laboratory Fume Hood',Journal of Occupational and Environmental Hygiene,3:12,694 — 706 To link to this Article: DOI: $10.1080 / 15459620601015695$

URL: http://dx.doi.org/10.1080/15459620601015695

\section{PLEASE SCROLL DOWN FOR ARTICLE}

\footnotetext{
The American Conference of Governmental Industrial Hygienists (http://www.acgih.org/) and the American Industrial Hygiene Association (http://www.aiha.org/) have licensed the Taylor \& Francis Group to publish this article and other materials. To join the American Conference of Governmental Industrial Hygienists visit http://www.acgih.org/Members/. To join the American Industrial Hygiene Association visit http://www.aiha.org/Content/BecomeMember/becomemember-splash.htm.

Full terms and conditions of use: http://oeh.informaworld.com/terms-and-conditions-of-access.pdf

This article maybe used for research, teaching and private study purposes. Any substantial or systematic reproduction, re-distribution, re-selling, loan or sub-licensing, systematic supply or distribution in any form to anyone is expressly forbidden.

The publisher does not give any warranty express or implied or make any representation that the contents will be complete or accurate or up to date. The accuracy of any instructions, formulae and drug doses should be independently verified with primary sources. The publisher shall not be liable for any loss, actions, claims, proceedings, demand or costs or damages whatsoever or howsoever caused arising directly or indirectly in connection with or arising out of the use of this material.
} 


\title{
Correlation Between Airflow Patterns and Performance of a Laboratory Fume Hood
}

\author{
Li-Ching Tseng, ${ }^{1}$ Rong Fung Huang, ${ }^{2}$ Chih-Chieh Chen, ${ }^{1}$ and C.-P. Chang ${ }^{3}$ \\ ${ }^{1}$ Institute of Occupational Medicine and Industrial Hygiene, National Taiwan University, Taipei, Taiwan \\ ${ }^{2}$ Department of Mechanical Engineering, National Taiwan University of Science and Technology, \\ Taipei, Taiwan \\ ${ }^{3}$ Institute of Occupational Safety and Health, Council of Labor Affairs, Sijhih City, Taiwan
}

\begin{abstract}
To understand the physical mechanisms of the contaminant dispersion and containment leakage during the ventilation process through a laboratory fume hood, the complicated threedimensional flow patterns and the real-time tracer gas $\left(S_{6} F_{6}\right)$ leakage were studied via the laser-assisted flow visualization method and the standard/special gas sampling technique, respectively. Through flow visualization, the large-scale vortex structures and boundary layer separations were found around the side poles and doorsill of the hood. In the near-wake region of the manikin, large recirculation zones and wavy flow structures were also identified. When tracer gas concentration measurements were conducted point-by-point across the sash opening, the areas near the doorsill, the lower parts of the side poles, and the sides of the manikin showed significant contaminant leaks. These areas with high contaminant leaks exactly corresponded to where the flow recirculated or separated. However, when the ANSI/ASHRAE 110-1995 protocol was used to measure the concentration of $\mathrm{SF}_{6}$ at the breathing zone of the manikin, no appreciable leakage was detected. It is suggested that a method based on the aerodynamic features and multipoint leakage detections would reflect a more realistic evaluation of overall performance of laboratory fume hood than a single-point sampling method at the manikin's breathing zone.
\end{abstract}

Keywords laboratory fume hood, performance, smoke visualization, tracer gas, turbulence

Address correspondence to: Rong Fung Huang, Department of Mechanical Engineering, National Taiwan University of Science and Technology, 43 Keelung Road, Section 4, Taipei, Taiwan, R.O.C.; e-mail: rfhuang@mail.ntust.edu.tw.

\section{INTRODUCTION}

A laboratory fume hood is a box-like structure with an adjustable front opening. It is designed to capture, contain, and remove harmful fumes generated inside the enclosure. The performance and characteristics of laboratory fume hoods have been widely studied during the past few decades. Previous studies $^{(1-7)}$ have suggested that operating the hood at a high face velocity does not ensure a high hood containment efficiency because no correlation between the face velocity and the hood performance was observed. The primary physical mechanism leading to contaminant leakage, therefore, may not be the global parameter of the suction flow rate or the flow distribution. Instead, the detailed flow structure may play a significant role and require systematic investigation.

Earlier studies ${ }^{(8-14)}$ on the local, detailed flow structure concentrated mainly on the use of numerical analysis to predict flow patterns through laboratory fume hoods. Turbulent flow has been recognized as a significant factor contributing to contaminant leakage. Therefore, a better understanding of the underlying dynamics of the basic structures in turbulent flow to describe the transport mechanism of contaminant is required, but detailed experimental data on this subject and the extent of understanding the physical mechanisms governing contaminant leakage during the ventilation process are limited and warrant further investigations.

The ANSI/ASHRAE 110-1995 Method of Testing Performance of Laboratory Fume Hoods provides a test mthod that is both quantitative and qualitative for evaluating the containment of laboratory fume hoods. ${ }^{(15)}$ This widely accepted protocol consists of a three-part evaluation process that included a face velocity test, flow visualization, and a tracer gas test. This test method was developed as an attempt to measure the breathing zone exposure of a fume hood operator. Accordingly, the concentration at the breathing zone is representative of the concentration inhaled by a person in front of a laboratory fume hood. However, the test protocol does not account for important aerodynamic features of fume hood operating exposure.

In this study, the time-averaged face velocity, the velocity fluctuation, and the real-time tracer gas concentration along the face of the hood were measured. The laser light sheetassisted flow visualization method was first incorporated to provide details of the flow patterns inside and around the sash opening of the fume hood. The data was used for guiding the subsequent quantitative containment experiments. The effects of the fume hood geometry and the presence of the manikin on 


\section{NOMENCLATURE}

$C_{\mathrm{SF} 6} \quad$ concentration of $\mathrm{SF}_{6}$, in ppm

$H \quad$ operating sash height of fume hood

$H_{0} \quad$ designed maximum sash height of fume hood

$Q \quad$ volumetric suction flow rate of fume hood

$V_{0} \quad$ face velocity of fume hood $(=Q /$ area of sash opening)
$W \quad$ width of hood opening in sash plane

$X \quad$ horizontal coordinate originated at left side boundary of hood opening in sash plane

$Y \quad$ vertical coordinate originated at left side boundary of hood opening in sash plane

Z normal coordinate originated at left side boundary of hood opening in sash plane the contaminant leakages evaluated by tracer gas concentration measurement methods were investigated. By comparing the results of the flow structures and the tracer-gas tests, the physical mechanism leading to the contaminant leakage is discussed and a strategy for testing the laboratory fume hood with considerations of the local leakage instead of the singlepoint test around the worker's breathing zone is suggested.

\section{EXPERIMENTAL METHODS}

$\Gamma$ he experimental study included two parts: the laboratory test and the on-site measurements.

\section{Laboratory Test Apparatus}

The experimental setup included a laboratory fume hood model, an extract fan, and instruments, as shown in Figure 1. The prototype fume hood used for the test was made of transparent acrylic plates so laser beams could pass through. The height and width of the working aperture of the test fume hood were $850 \mathrm{~mm}$ and $1200 \mathrm{~mm}$, respectively. The suction flow rate was measured by a homemade Venturi flow meter and a calibrated pressure gauge. The accuracy of the suction flow rate measurement was less than $1 \%$ of the reading. Experiments were carried out in a well-controlled test room that was $19 \mathrm{~m}^{3} \times$ $17 \mathrm{~m}^{3} \times 5 \mathrm{~m}^{3}$. During the experiment, the interference induced

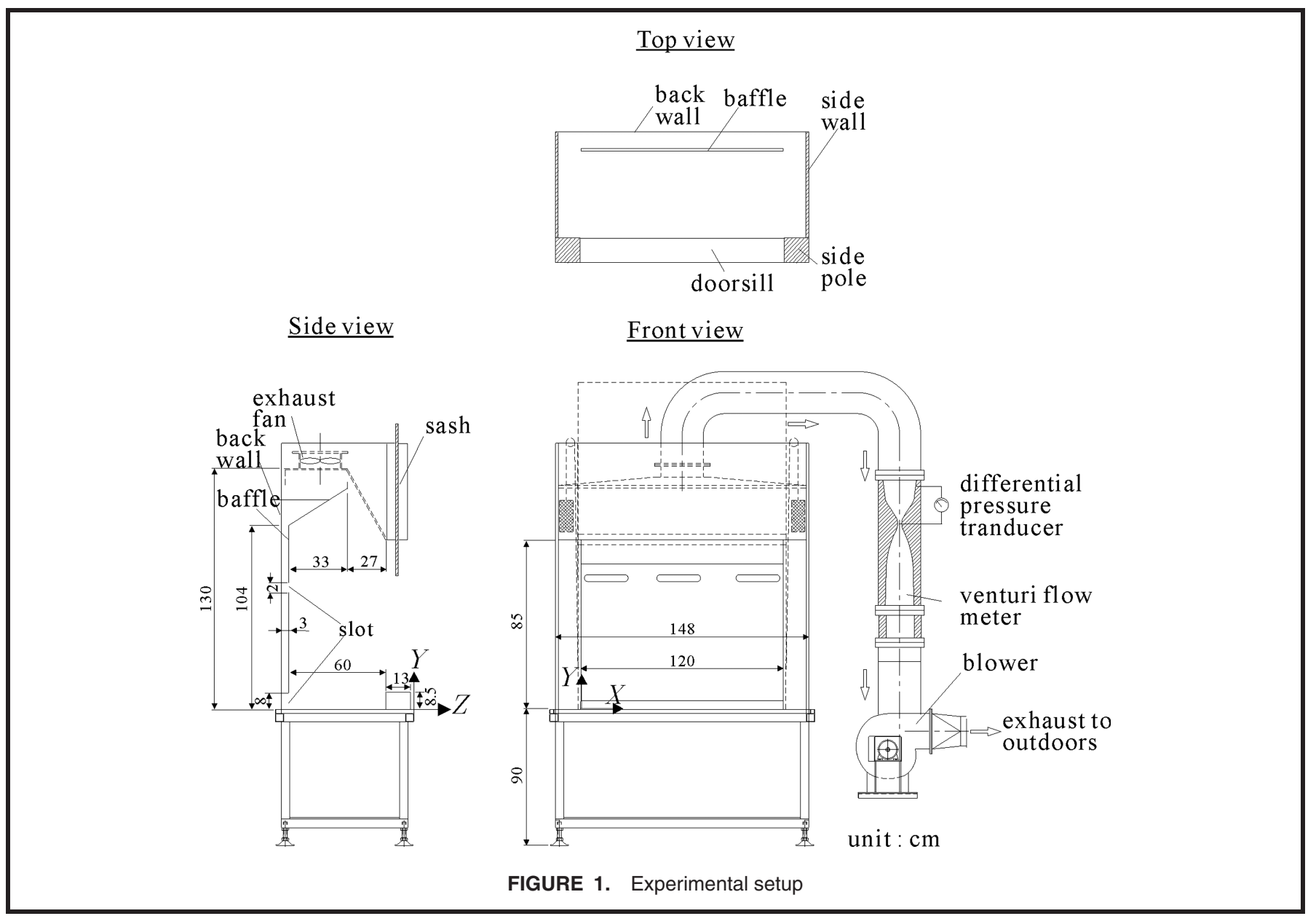




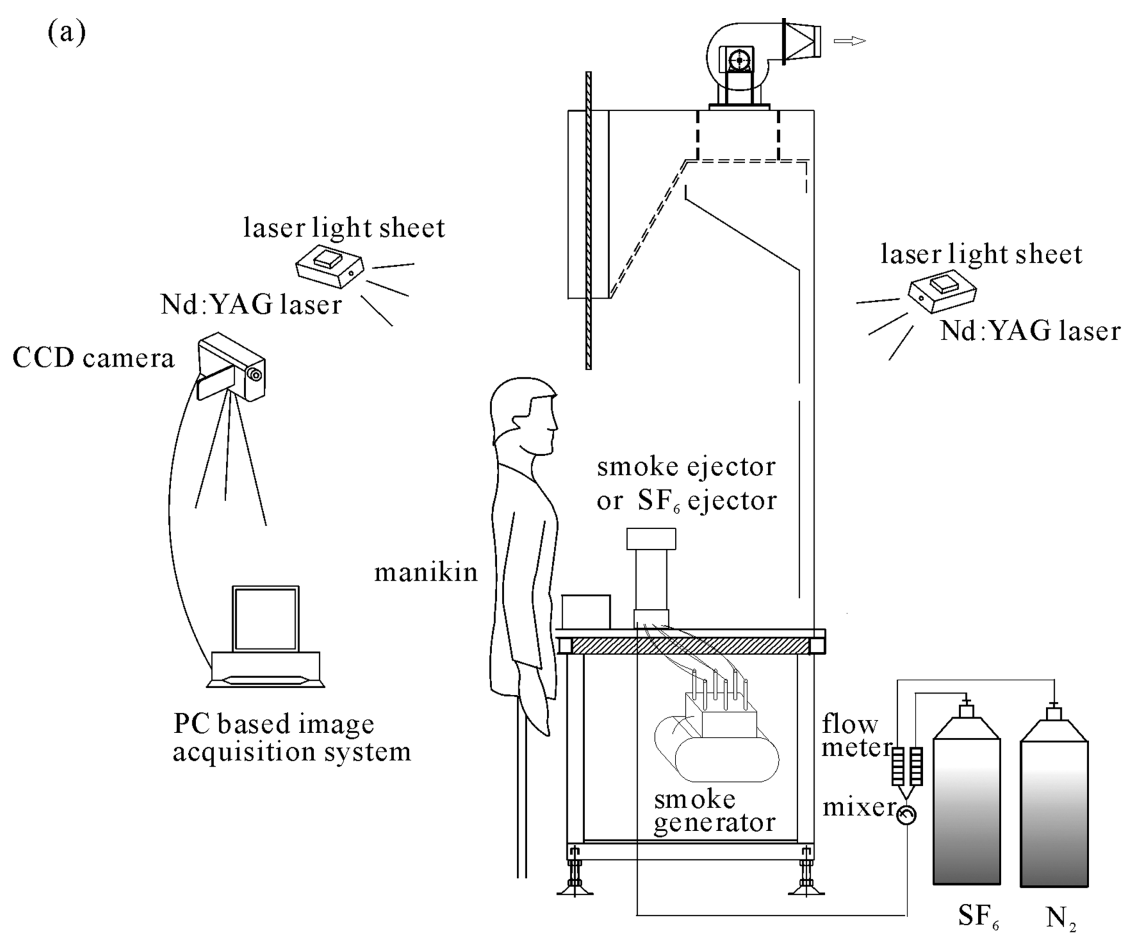

(b)
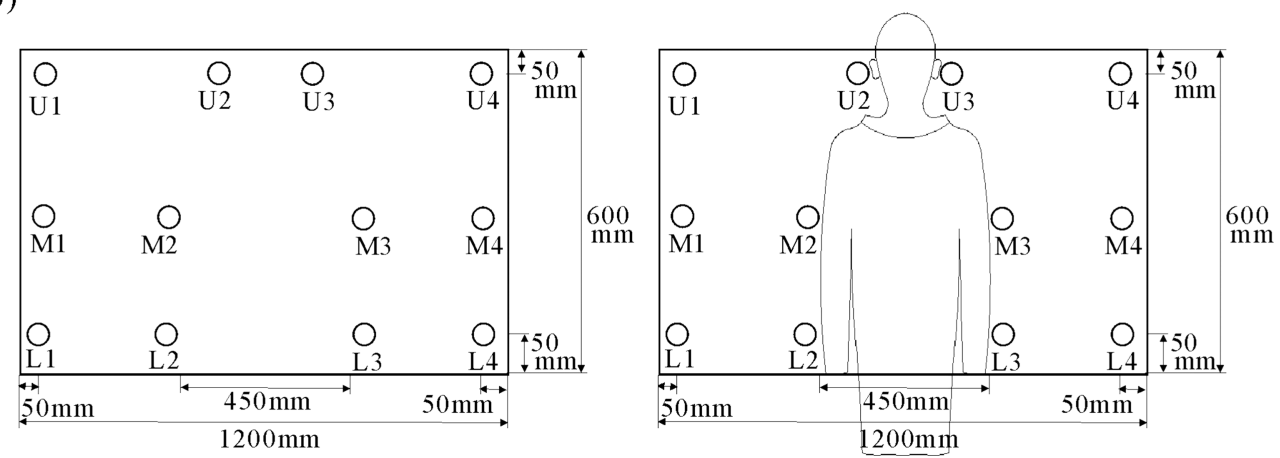

FIGURE 2. Experimental setup; (a) apparatus for flow visualization and tracer gas test, (b) test grid arrangement

by the external sources such as the air supply diffusers, doors, and traffic in the room was restricted.

\section{Flow Visualization}

An experiment of flow visualization was conducted at a sash height of $600 \mathrm{~mm}$. The face velocity $V_{0}$ was set at $0.5 \mathrm{~m} / \mathrm{sec}$. Paraffin oil mist was continuously delivered to the smoke ejector of a small-diameter, stainless steel tube from a homemade smoke generator. The smoke ejector (or smoke tube) was placed in the hood at the proper position to release the smoke and scatter the laser light, as shown in Figure 2a. The Stokes number of the smoke particles was in the order of magnitude of $10^{-6}$ and could, therefore, properly follow the flow fluctuations up to at least $10 \mathrm{kHz}$.

The streams of the smoke were discharged by two different means. (1) For simulating the contaminant transport process, the smoke was released through a smoke ejector that was made following the ANSI/ASHRAE 110-1995 method for tracer gas measurement, as shown in Figure 2a. Both the positioning of the smoke ejector and the release rate of the smoke flow all followed the ANSI/ASHRAE 110-1995 protocol for tracer gas measurement. (2) For better visualization of local flow structure in some target regions, the smoke was released at a velocity lower than $0.05 \mathrm{~m} / \mathrm{sec}$ through a small-diameter $(4 \mathrm{~mm}$ ) stainless steel tube positioned around the target regions. The laser beam emitted from a Nd:YAG laser (Dpss Green Laser AMGC-100, Onset Electro-Optics Corp., Taipei, Taiwan) was transmitted through an optical fiber and connected to a $20^{\circ}$ laser light sheet expander. The particle images were recorded by a CCD camera (DCR-TRV 900, Sony Corp., Japan) that was equipped with an asynchronous variable electronic shutter so the exposure time could 
be adjusted from $1 / 12000 \mathrm{sec}$ to $1 / 30 \mathrm{sec}$ at a framing rate of $30 \mathrm{ft} / \mathrm{sec}$.

Experiments were performed for both "occupied hood" (with a manikin standing in front of the hood) and "unoccupied hood" (without the manikin) to examine the effect induced by the presence of the manikin.

\section{Tracer Gas Test}

The experiment was conducted at sash heights of $600 \mathrm{~mm}$ and $850 \mathrm{~mm}$. The face velocity $V_{0}$ was set at $0.5 \mathrm{~m} / \mathrm{sec}$. The tracer gas ejector position, flow rate, and manikin placement were the same as those used in the flow visualization, as shown in Figure 2a. The tracer gas ejector was fabricated following the ANSI/ASHRAE 110-1995 test standard. The mean and peak values of $\mathrm{SF}_{6}$ concentration were measured and recorded with a high precision infrared detector (MIRAN SapphIRe Ambient Air Analyzer, Thermo Electron Corp., Franklin, Mass.). The detection range from 0 to $4 \mathrm{ppm}$ was calibrated by the manufacturer and checked in the laboratory before use. The results of the laboratory check showed good agreement with the factory calibration in this range. The detection ranges from 4 to 100 ppm were calibrated in the laboratory.

Separated calibration curves and regression formulas were obtained for the ranges 4-37 ppm and 37-100 ppm. The maximum deviations of the calibration curves from the supplied standard concentration values were $10 \%$ of the reading for the range $0-1 \mathrm{ppm}, 20 \%$ of the reading for the range $1-4 \mathrm{ppm}$, and $12 \%$ of the reading for the range $4-100 \mathrm{ppm}$. The output data could be set on the control panel to ppm with a resolution of $0.01 \mathrm{ppm}$ or to $\mathrm{ppb}$ with a resolution of $1 \mathrm{ppb}$. In this study, the resolution was set to ppm. The sampling flow rate was 14 $\mathrm{L} / \mathrm{min}$, the internal sample rate of the detector was $20 \mathrm{~Hz}$, and the average value over a 10 -sec period was recorded as one reading.

The experimental procedures were conducted in accordance with Test Mode A and Test Mode B of ANSI/ASHRAE 1101995.

Test Mode A. The tracer gas was $10 \%$ by volume fraction of sulfur hexafluoride $\left(\mathrm{SF}_{6}\right)$ in nitrogen. Tracer gas samples were taken point-by-point over the 12 locations in a rectangular area in the sash opening plane through a $13 \mathrm{~mm}$ i.d. stainless steel tube, as shown in Figure 2b. Both the occupied hood and the unoccupied hood were tested. Sampling was taken for 480 $\mathrm{sec}$, and the data for the initial period of $180 \mathrm{sec}$ was discarded.

Test Mode B. Measurements were conducted following the ANSI/ASHRAE 110-1995 test protocol by using $100 \%$ $\mathrm{SF}_{6}$ as the tracer gas. The manikin with the same shape and size as described in the flow visualization method was placed in position. Tracer gas samples were taken through a $13 \mathrm{~mm}$ i.d. stainless steel tube. The detector probe was arranged to penetrate through the head of the manikin so that the suction tip was fixed below the nose. The center of the probe was 660 $\mathrm{mm}$ above the work surface and $75 \mathrm{~mm}$ in front of the sash. The detector readings were recorded for $300 \mathrm{sec}$ while the tracer gas was released into the hood.

\section{On-Site Measurement}

The relationship between face velocity and flow patterns to the tracer gas leakage was investigated on nine laboratory fume hoods randomly selected from nine universities in Taiwan. The mean face velocity measurement, flow visualization, and tracer gas test following the same procedure of the laboratory test were carried out.

\section{RESULTS AND DISCUSSION}

\section{Effect of Hood Geometry}

Figure 3 shows the side-viewed smoke flow pattern across the symmetry plane of the hood when the sash height $H$ was set at $600 \mathrm{~mm}$. A large, counterclockwise-rotating vortex was observed behind the sash when smoke was released from a smoke tube placed behind the sash. This large-scale flow structure was induced by the separation of boundary layer occurring at the bottom edge of the sash when the airflow was drawn through the sash opening into the cabinet. Unsteady, complex, threedimensional vortices were formed there. If the smoke was released from the smoke ejector placed on the work surface (which meant smoke was not released from the smoke tube behind the sash), the large recirculation bubble would become invisible. Instead, smoke released from the smoke ejector was drawn to the back of the cabinet and expelled through the bottom slot of the baffle. The flow pattern of Figure 3 implies that although a large recirculation bubble may have existed in the back of the sash, the contaminants released from the lower level of the cabinet may not have had the opportunity to disperse drastically up to the recirculation bubble behind the sash.

Figures $4 \mathrm{a}$ and $4 \mathrm{~b}$ show the flow patterns around the right side wall and side pole. The laser light sheets were arranged across the horizontal planes on the middle and lower levels. Smoke was released from a smoke tube placed behind the doorsill near the right lower corner of the cabinet. The smoke was not drawn directly to the back of the cabinet. Instead, it was carried by an internal lateral stream to the area near the side wall, where some characteristic flow structures were observed. The flow in that region was very turbulent; the recirculation motion of the smoked flow was apparent.

Therefore, three-dimensional flow structure must exist in the cabinet, otherwise the smoke would not appear there. When the flow passed over the front edge of the side pole, the boundary layer separated. The separated boundary layer evolved from the edge of the side pole and entrained smoke from the region near the side wall so that the region near the side pole, which was outside the sash opening, was contaminated by the smoke. If contaminants in the cabinet recirculated to this area, dispersion through the shear layer out to the environment via the turbulent diffusion mechanism would be possible. ${ }^{(16)}$

Figure $4 \mathrm{c}$ shows the flow pattern around the doorsill. The laser light sheet was arranged vertically. When the environmental air was drawn into the cabinet, the boundary layer separated from the front edge of the doorsill and formed a recirculation zone behind the doorsill. A series of coherent flow structures 


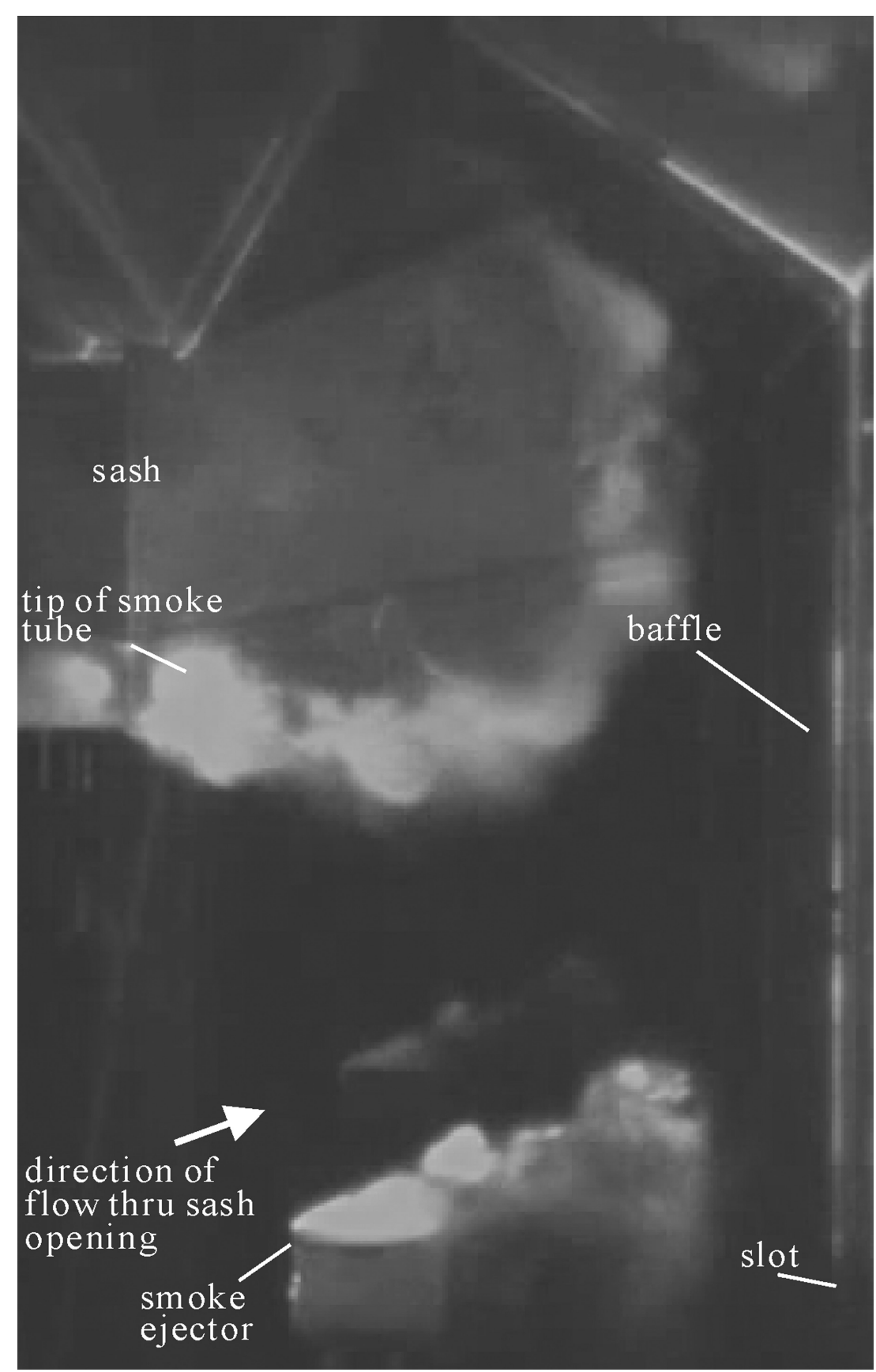

FIGURE 3. Side view of smoke patterns in interior of hood cabinet, $H=600 \mathrm{~mm}, V_{0}=0.5 \mathrm{~m} / \mathrm{sec}$

appeared in the shear layer. The region above the doorsill out of the sash opening was contaminated by the smoke. The flows in the recirculation zone were highly turbulent. It is very probable that the contaminants were carried to this region and diffused through the turbulent shear layer to the atmosphere.

Table I shows the results of the tracer gas experiments using Test Mode A. When sash height $H$ is set to either $600 \mathrm{~mm}$ or $850 \mathrm{~mm}$, the levels of $\mathrm{SF}_{6}$ leakages measured at the upper grids, i.e., the grids U1, U2, U3, and U4 shown in Figure 2b, were generally low for the unoccupied hood. On the middle level, substantially high $\mathrm{SF}_{6}$ concentrations were detected at grids M1 and M4, which were located near the side poles. $\mathrm{SF}_{6}$ concentrations detected at M2 and M3 were still low. On the lower level above the doorsill, all the detected $\mathrm{SF}_{6}$ concentrations were high. Particularly, at locations near the side poles (L1 and L4), containment leaks were much more severe than those detected at other positions. Obviously, under the condition of static test, the regions around the bottom edge of the sash and the middle region of the sash opening were not the most probable areas for containment spillage; the most highly probable areas existed in the regions around the side poles and the doorsill. 

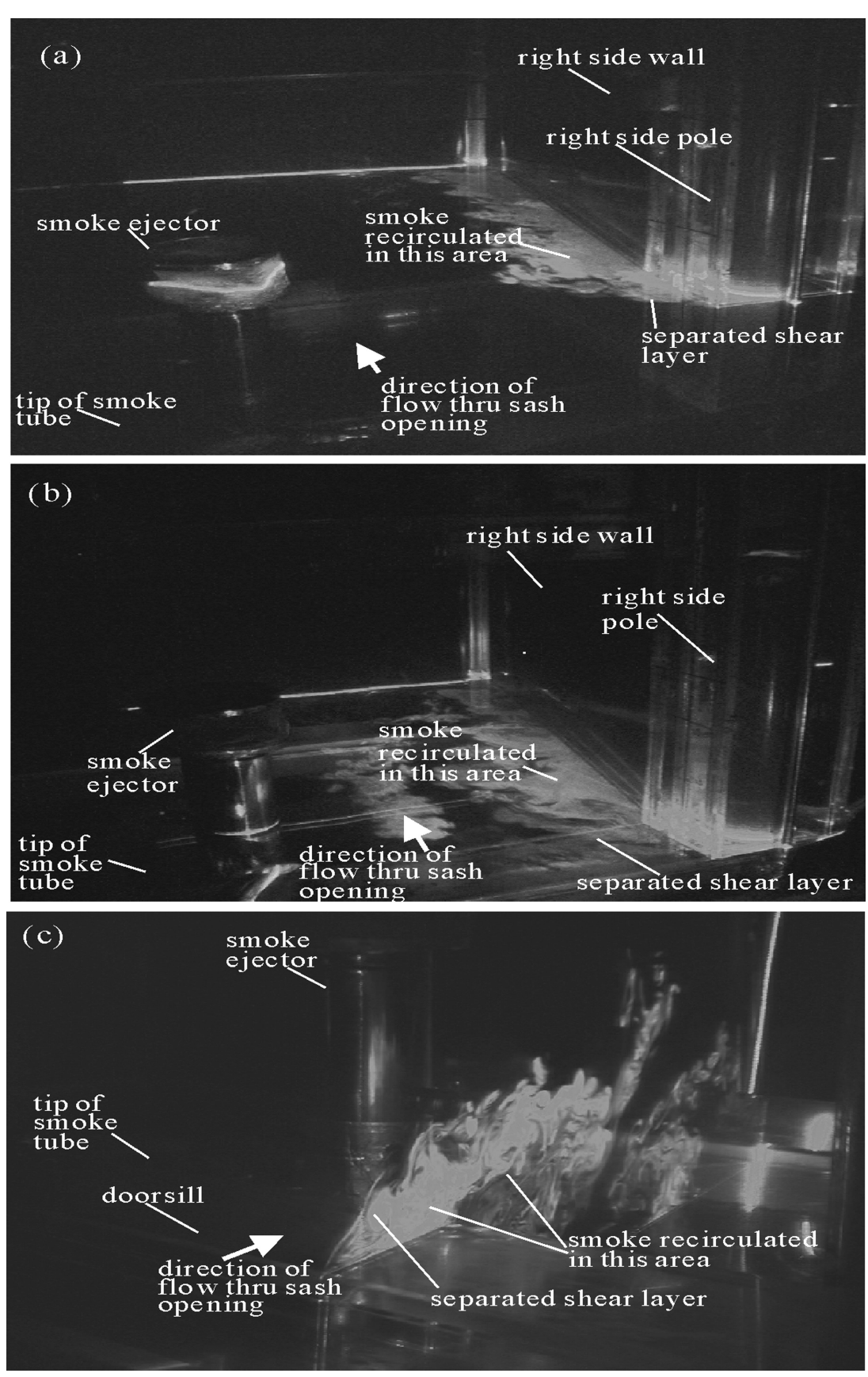

FIGURE 4. Smoke patterns near (a) middle level of side wall, (b) lower level around side right side pole and side wall, and (c) doorsill. $H=$ $600 \mathrm{~mm}, V_{0}=0.5 \mathrm{~m} / \mathrm{sec}$.

The results of the flow visualization experiment establish that the recirculation zones formed behind the sash and around the side poles and the doorsill were the most probable sources for containment leakage, as stated earlier. The aforementioned results of $\mathrm{SF}_{6}$ concentration tests reveal that severe contaminant leakage occured around the areas near the side poles and the doorsill. However, the $\mathrm{SF}_{6}$ concentrations detected directly beneath the bottom edge of the sash were relatively low. The three-dimensional flow motion in the cabinet, in conjunction with the separated boundary layers induced by the inappropriate design of hood geometry, induced flow recirculation. Unsteady turbulent dispersion was, therefore, one of the important causes for hood leakage. The separated shear layers around the side poles and the doorsill shown in Figure 4 (which consist of unsteady coherent flow structures and recirculated containments) were located outside the hood cabinet, whereas the large recirculating vortex behind the sash, as shown in Figure 2, was totally enclosed in the cabinet. 
TABLE I. SF $_{6}$ Concentrations Measured by Test Mode A (Point-by-Point Method)

\begin{tabular}{|c|c|c|c|c|}
\hline \multirow[b]{2}{*}{ Grid Position } & \multicolumn{2}{|c|}{$\mathrm{H}=600 \mathrm{~mm}$} & \multicolumn{2}{|c|}{$H=850 \mathrm{~mm}$} \\
\hline & $\begin{array}{c}\text { C }_{\text {SF6 }} \\
\text { Unoccupied Hood } \\
\text { Mean (peak), ppm }\end{array}$ & $\begin{array}{c}\text { C }_{\text {SF6 }} \\
\text { Occupied Hood } \\
\text { Mean (peak), ppm }\end{array}$ & $\begin{array}{c}\text { C }_{\text {SF6 }} \\
\text { Unoccupied Hood } \\
\text { Mean (peak), ppm }\end{array}$ & $\begin{array}{c}\mathrm{C}_{\mathrm{SF} 6} \\
\text { Occupied Hood } \\
\text { Mean (peak), ppm }\end{array}$ \\
\hline U1 & $0.04(0.05)$ & $0.26(0.66)$ & $0.08(0.14)$ & $0.14(0.54)$ \\
\hline $\mathrm{U} 2$ & $0.02(0.02)$ & $0.02(0.02)$ & $0.03(0.05)$ & $0.04(0.08)$ \\
\hline $\mathrm{U} 4$ & $0.03(0.06)$ & $1.63(2.43)$ & $0.08(0.28)$ & $2.85(6.84)$ \\
\hline M1 & $1.30(4.58)$ & $16.70(25.78)$ & $3.78(5.79)$ & $27.68(39.42)$ \\
\hline M2 & $0.01(0.01)$ & $0.01(0.01)$ & $0.02(0.03)$ & $0.05(0.07)$ \\
\hline M3 & $0.02(0.02)$ & $0.01(0.02)$ & $0.03(0.05)$ & $0.07(0.15)$ \\
\hline M4 & $1.14(3.24)$ & $22.42(31.76)$ & 3.05 (8.59) & $38.73(50.41)$ \\
\hline
\end{tabular}

Note: Averages were taken over the 3rd to 8 th min.

Therefore, the possibility of dispersion of the contaminants out into the atmosphere from the areas around the doorsill and the side poles would inevitably be higher than dispersion around the bottom edge of the sash. The airfoil structure or streamlined doorsill design commonly seen in commercial hoods may have positive effects on alleviating the formation of the doorsill boundary layer separation and, as a result, could reduce some containment spillage from that area if the arrangement is aerodynamically appropriate.

\section{Effect of Manikin Presence}

When smoke was released from the ejector, as shown in Figure 5a, none was found in the breathing zone of the manikin. As smoke was introduced to the area around the manikin's head, as shown in Figure 5b, the suction force developed by the fan drew the smoke directly into the hood chamber. No recirculation was found. The downwash current flushed downward from the head of the manikin was the primary flow physics responsible for the disappearance of the wake recirculation expected to appear there. The tracer gas measurements on the upper level grids for the occupied hood in Table I show that the values of $\mathrm{SF}_{6}$ concentration around the breathing zone of the manikin (grids U2 and U3) were quite low; concentrations were similar to those of the unoccupied hood. This result correlates well with the observation of flow patterns shown in Figure 5.

To examine flow around the chest of the manikin, smoke was released from the smoke ejector in the hood at the positions indicated in Figure 6a. No smoke was found in front of the manikin's chest. However, as the smoke was introduced into the area around the manikin's chest, as indicated in Figure $6 \mathrm{~b}$, the flow in front of the manikin's chest exhibited a large, recirculating flow zone. This large recirculation bub- ble was actually a "bluff-body wake" that was induced when air in the environment was drawn into the hood and across the manikin (the manikin is a bluff body from the viewpoint of aerodynamics). The recirculation bubble extended into the hood and may have transported the contaminant to the area near the manikin's chest. The characteristic flow structure induced by the flow across a circular cylinder has been studied experimentally. ${ }^{(17,18)}$

These studies reveal that the presence of a bluff body (e.g., the manikin) can create a wake zone with recirculation and vortex shedding. The wake zone could draw contaminants from the regions in the hood where they might build up. This phenomenon is inevitable in fume hoods of conventional design because the flow drawn into the sash opening always has a horizontal component that would make the Reynolds number based on the shoulder width of the manikin generally larger than 10000. In Table I, the results of the tracer gas measurements for the occupied hood on the middle level show that the values of $\mathrm{SF}_{6}$ concentration around the chest sides (grids M2 and M3) were not significantly larger than their counterparts for the unoccupied hood.

The existence of chest recirculation seems not to have entrained the $\mathrm{SF}_{6}$ out of the hood, which is in contrast to the expectation obtained from the flow visualization result of Figure $6 \mathrm{~b}$. This may be because the $\mathrm{SF}_{6}$ released from the ejector was drawn through the slots of the baffle and did not have opportunity to disperse up to the recirculation zone, as illustrated in Figure 6a. However, this may not apply to all hood designs. The chest recirculation is still a dangerous flow structure that could cause contaminant leakage.

When the manikin was placed in front of the hood, highly unstable recirculation zones and wavy structures were observed in the horizontal and vertical planes around the side 

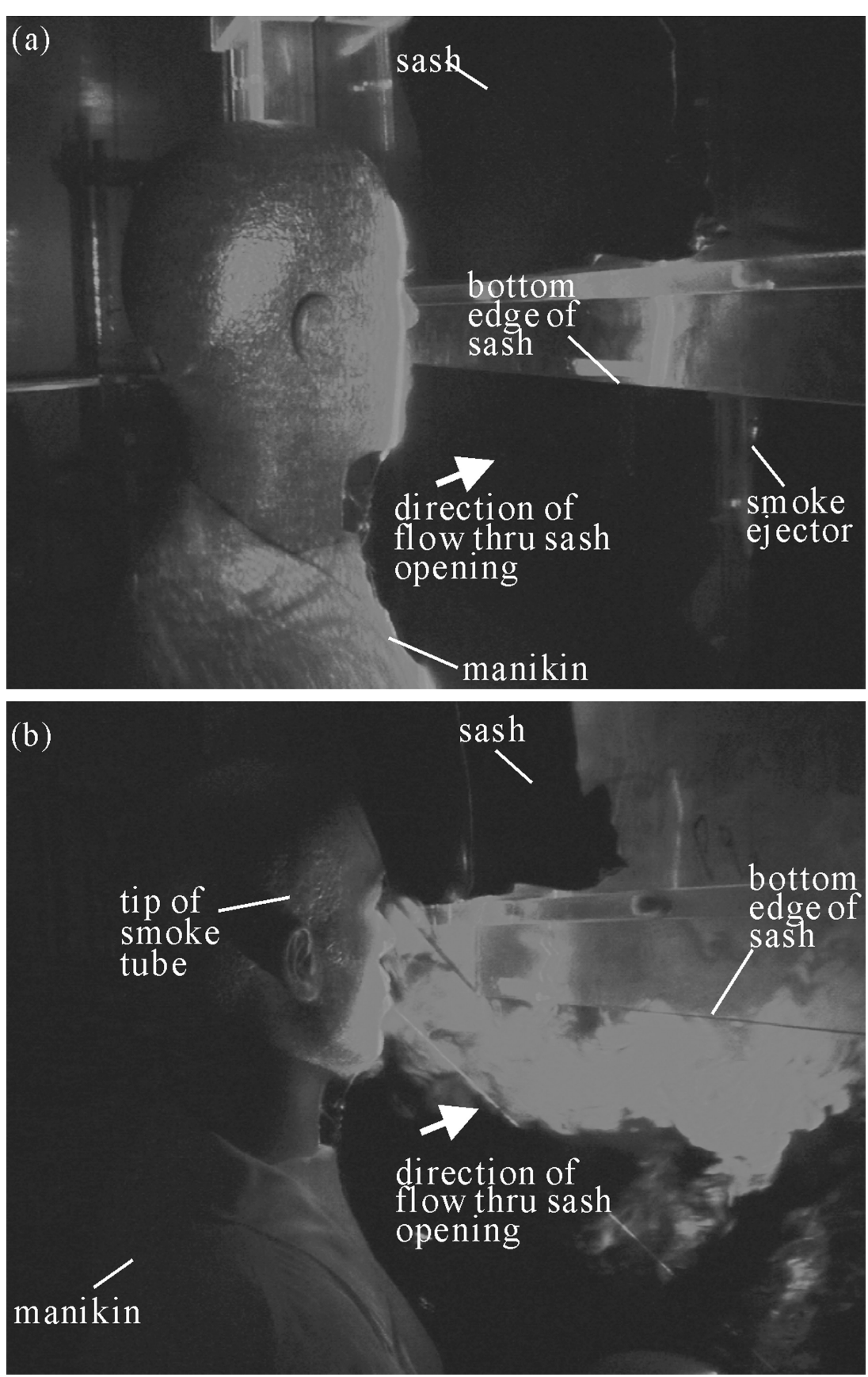

FIGURE 5. Smoke patterns around breathing-zone of manikin. Smoke released from (a) smoke ejector placed in cabinet, (b) head side of manikin. $H=600 \mathrm{~mm}, V_{0}=0.5 \mathrm{~m} / \mathrm{sec}$.

corner and doorsill area, as shown in Figures $7 \mathrm{a}$ and $7 \mathrm{~b}$, respectively. These flow patterns were similar to those observed in the case of the unoccupied hood shown in Figures $4 \mathrm{~b}$ and $4 \mathrm{c}$. By comparing Figures $7 \mathrm{a}$ and $7 \mathrm{~b}$ with Figures $4 \mathrm{~b}$ and $4 \mathrm{c}$, the recirculation zones induced by the flow separation when the manikin was present are apparently larger than those of the unoccupied hood. The presence of the manikin seems to have had the effect of enhancing the intensity and size of the separation and recirculation zones around the middle and the lower levels of the hood.
The tracer gas test results of Table I support the evidence of the visual findings. In grids M1 and M4 (near the side poles) on the middle level, the occupied hood exhibited much larger containment spillage than the unoccupied one. For instance, for $H=600 \mathrm{~mm}, C_{\mathrm{SF} 6}=16.70 \mathrm{ppm}$ was detected at $\mathrm{M} 1$ and $22.42 \mathrm{ppm}$ at $\mathrm{M} 4$, whereas for the unoccupied hood, $\mathrm{SF}_{6}$ concentrations were only $1.30 \mathrm{ppm}$ at $\mathrm{M} 1$ and $1.14 \mathrm{ppm}$ at M4. On the lower level, the containment spillage was substantially much more severe when the manikin was present, e.g., at the right corner (L4), the sampled $\mathrm{SF}_{6}$ concentration 

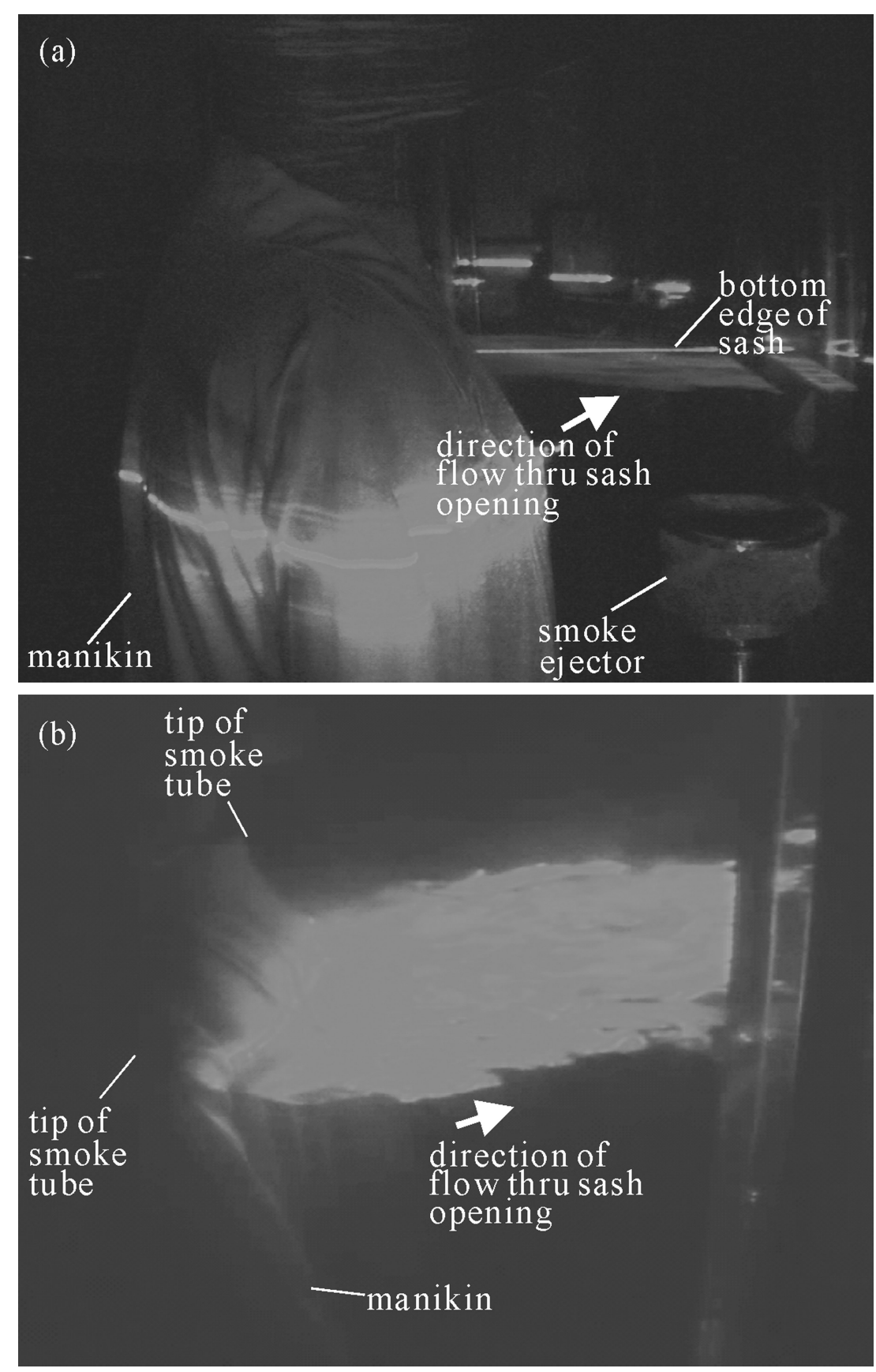

FIGURE 6. Smoke patterns in front of chest of manikin. Smoke released from (a) smoke ejector placed in cabinet, (b) chest side of manikin. $H=600 \mathrm{~mm}, V_{0}=0.5 \mathrm{~m} / \mathrm{sec}$.

at the presence of the manikin attained $77.65 \mathrm{ppm}$, which was drastically larger than 1.88 ppm of the unoccupied hood. The interaction between the recirculation bubble in the manikin wake and the separated shear layer above the doorsill also caused large contaminant leakages. For example, at L2 and L3 (Table I) the detected $\mathrm{SF}_{6}$ concentrations in the occupied hood were substantially higher than those in the unoccupied hood. Figure 8 shows the time histograms of the recorded $\mathrm{SF}_{6}$ concentrations at L1-L4 for both the unoccupied and occupied hoods. The presence of the manikin caused drastic increase of the time-averaged leakage levels when compared with levels in the unoccupied hood. Also, the fluctuations of the measured $\mathrm{SF}_{6}$ concentrations of the occupied hood were critically larger than those of the unoccupied one, which shows the unsteady characteristics of the containment dispersion induced by the increased turbulence levels.

\section{Discussion of the ANSI/ASHRAE 110-1995 Method}

As shown in Table II, the measured time-averaged mean concentrations of $\mathrm{SF}_{6}$ at the breathing zone of the manikin 

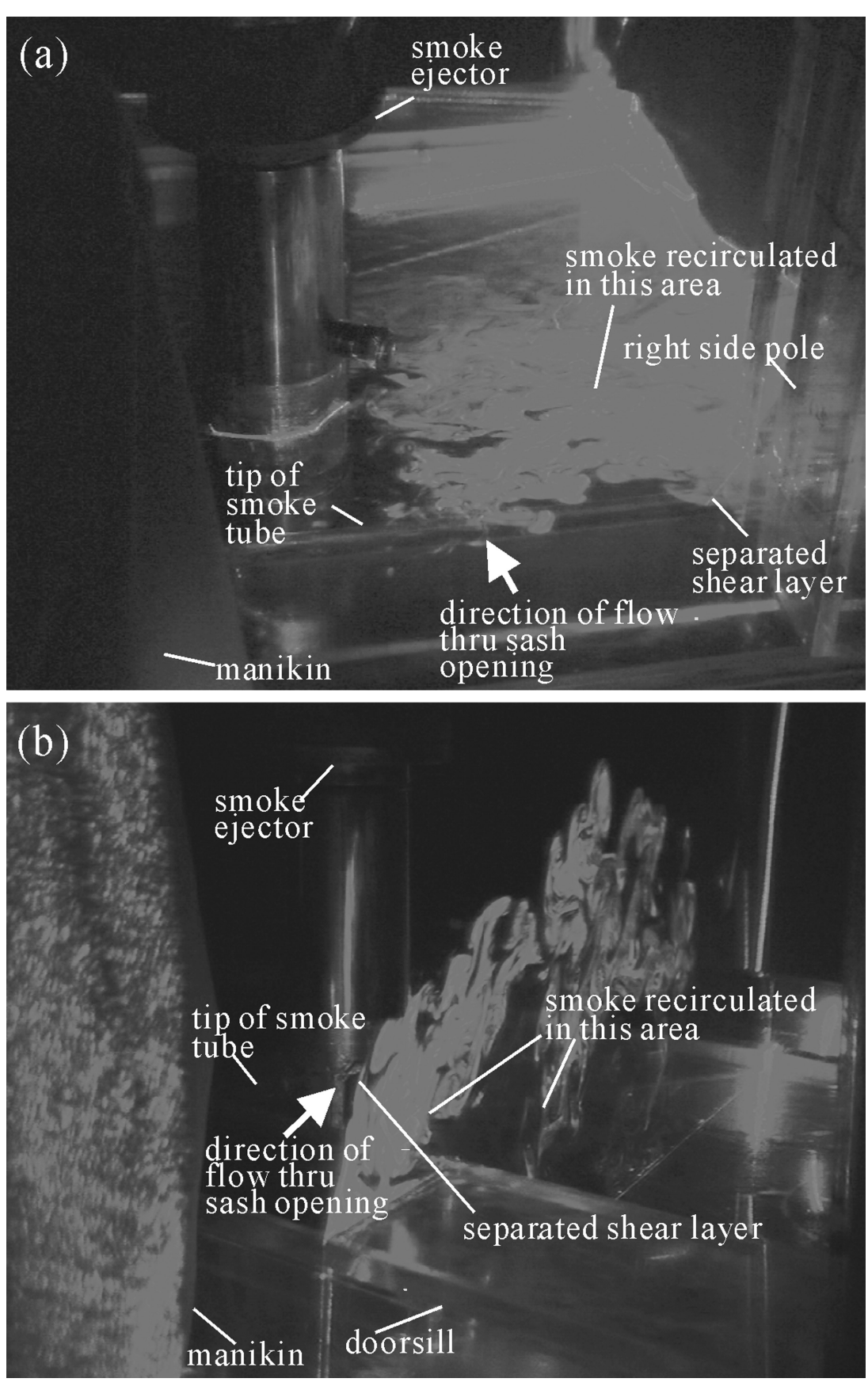

FIGURE 7. Smoke patterns near (a) lower level around side right pole and side wall, (b) doorsill. Manikin placed in front of hood. $H=600$ $\mathrm{mm}, V_{0}=0.5 \mathrm{~m} / \mathrm{sec}$

using the ANSI/ASHRAE 110-1995 method were less than $0.01 \mathrm{ppm}$ for $H=600 \mathrm{~mm}$ and lower than $0.02 \mathrm{ppm}$ for $H=$ $850 \mathrm{~mm}$. These levels are almost undetectable and far below the containment leakage threshold $(0.05 \mathrm{ppm})$ recommended by ANSI Z 9.5-2003 ${ }^{(19)}$ for the class of "as manufactured (AM)." The hood employed for the current investigation was a basic-type fume hood, which means no bypass design inside the hood above the sash, no auxiliary air near the face of the hood above the worker, no doorsill airfoil installation, no doorsill compensation air, no variable air volume (VAV) operation, no adaptive back baffle for sash vortex manipulation (e.g., the Bi-stable Vortex Fume Hood), and no vortex-isolation technique (e.g., the Berkeley Hood), etc. The hood passed the ANSI/ASHRAE 110-1995 test, although it presented severe containment leakages from the regions around the side poles and doorsill by using the point-by-point diagnostic method described in previous sections.

This result is not unexpected according to the arguments and discussions made previously. In the ANSI/ASHRAE 1101995 test, the tip of the sampling probe was positioned under 


\begin{tabular}{|c|c|c|c|c|}
\hline \multirow{2}{*}{$\begin{array}{c}\text { Grid } \\
\text { Position }\end{array}$} & \multicolumn{2}{|c|}{ Unoccupied hood } & \multicolumn{2}{c|}{ Occupied hood } \\
\cline { 2 - 5 } & $\begin{array}{c}\text { Average (ppm) } \\
\text { 3-8 min }\end{array}$ & $\begin{array}{c}\text { RMS (\%) } \\
\text { 3-8 min }\end{array}$ & $\begin{array}{c}\text { Average (ppm) } \\
\text { 3-8 min }\end{array}$ & $\begin{array}{c}\text { RMS (\%) } \\
\text { 3-8 min }\end{array}$ \\
\hline L1 & 1.14 & 1.08 & 24.65 & 5.44 \\
\hline L2 & 0.26 & 0.17 & 5.76 & 8.52 \\
\hline L3 & 0.39 & 0.91 & 22.14 & 13.69 \\
\hline L4 & 1.88 & 1.61 & 77.65 & 12.65 \\
\hline
\end{tabular}

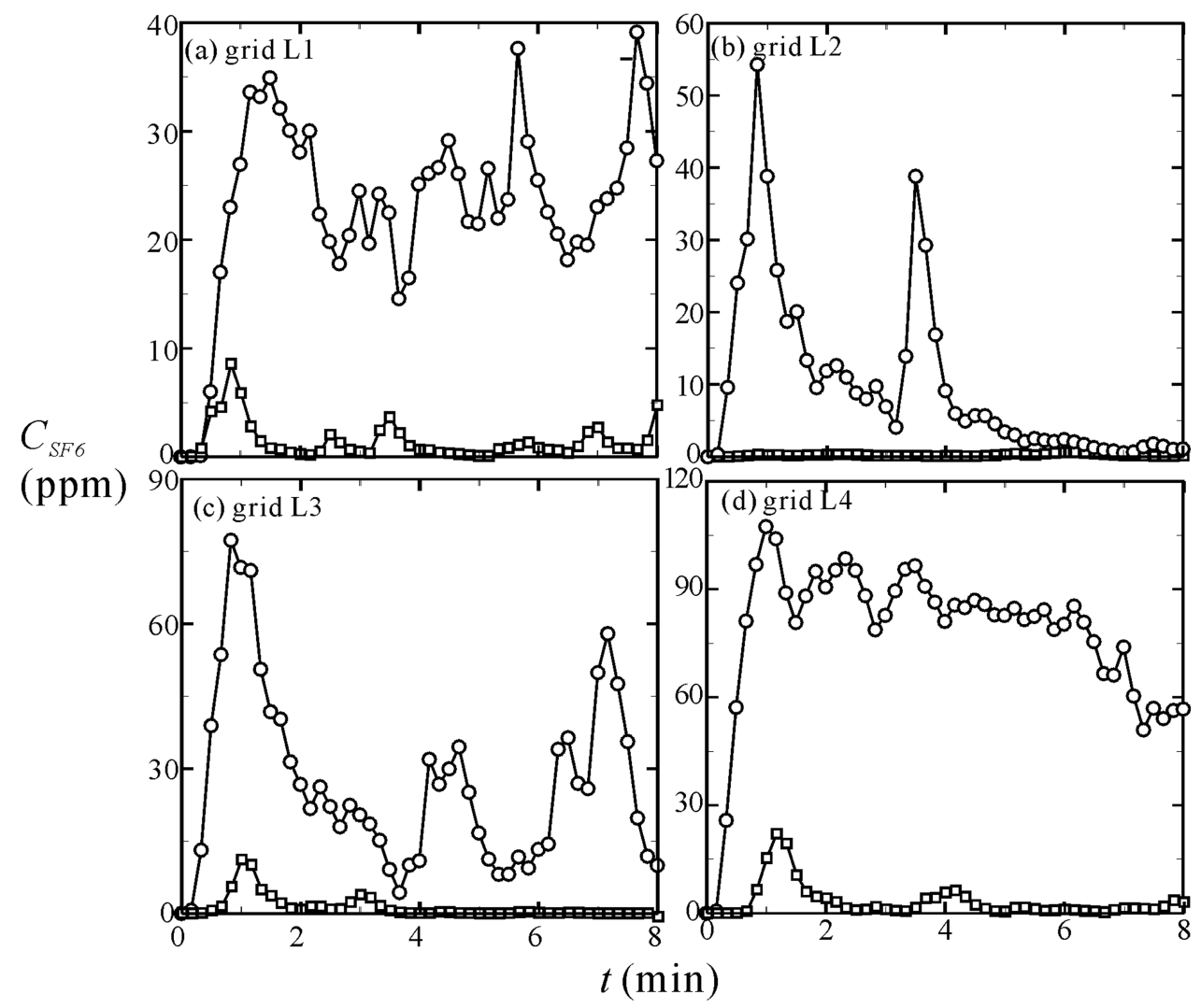

FIGURE 8. Time histograms of $\mathrm{SF}_{6}$ leakages of unoccupied and occupied hood at lower lever grids. (a) $\mathrm{L} 1$, (b) $\mathrm{L} 2$, (c) $\mathrm{L} 3$, (d) $\mathrm{L} 4$. $H=600$ $\mathrm{mm}, V_{0}=0.5 \mathrm{~m} / \mathrm{sec}$.

the nose of the manikin and was at a distance $75 \mathrm{~mm}$ away from the sash plane; whereas the data listed in Table I were obtained by positioning the tip of the sampling probe on the sash plane, using Test Mode A. Although the concentration of $\mathrm{SF}_{6}$ released from the ejector by following the ANSI/ASHRAE 110-1995 protocol was $100 \%$, the containment leakage was still difficult to detect around the breathing zone of the manikin. Nevertheless, as discussed previously, severe contaminant leakages occurred in the regions near the side poles and the doorsill regardless of whether the manikin was present. The representative samples measured in the breathing zone by using the ANSI/ASHRAE 110-1995 method seemed not to reflect accurately the overall behavior of the contaminant leakage through the hood.

The sampling strategy of the method focuses on detecting the concentration of $\mathrm{SF}_{6}$ in the breathing zone of the manikin by releasing the tracer gas ejector from a height of about $350 \mathrm{~mm}$ from the work surface. It does not ensure the detection of the most probable areas of containment leakage around a fume cupboard. Based on results of the present investigation, when satisfactory containment results are obtained by following the ANSI/ASHRAE 110-1995 protocol, it should be conservatively claimed that the tested hood has "good" performance because the point-by-point measurements across the whole sash opening may reveal results in contrast to the conclusion.

\section{On-Site Measurement Results}

Table III shows the in situ test results of nine fume hoods randomly selected from nine universities in Taiwan. Fume hood $\mathrm{A}$ has a face velocity $\left(V_{0}\right)$ lower than $0.30 \mathrm{~m} / \mathrm{sec}$. Fume hoods $\mathrm{B}-\mathrm{G}$ have a face velocity ranging from $0.30-0.50 \mathrm{~m} / \mathrm{sec}$. Fume hoods $\mathrm{H}$ and I have a face velocity greater than $0.5 \mathrm{~m} / \mathrm{sec}$. The results of tracer gas tests using Test Mode A and B were compared. Test Mode A (point-by-point method) results show 
TABLE II. SF 6 Concentrations Measured by Test Mode B, ANSI/ASHRAE 110-1995 Method

\begin{tabular}{lcc}
\hline & $\begin{array}{c}\mathbf{H}=\mathbf{6 0 0} \mathbf{~ m m} \\
\mathbf{C}_{\text {SF6 }}\end{array}$ & $\begin{array}{c}\mathbf{H}=\mathbf{8 5 0} \mathbf{~ m m} \\
\mathbf{C}_{\mathbf{S F 6}}\end{array}$ \\
$\begin{array}{l}\text { Test Time Interval } \\
\text { (min) }\end{array}$ & $\begin{array}{c}\text { Mean (peak), } \\
\mathbf{p p m}\end{array}$ & $\begin{array}{c}\text { Mean (peak), } \\
\mathbf{p p m}\end{array}$ \\
\hline $0-5$ & $<0.01(0.01)$ & $0.01(0.02)$ \\
$3-8$ & $<0.01(0.01)$ & $0.02(0.02)$ \\
\hline
\end{tabular}

extremely high containment leakage. However, when Test Mode B (ANSI/ASHRAE 110-1995 method) was employed, the measured $\mathrm{SF}_{6}$ concentrations were generally much lower than those obtained by Test Mode A. Two of the nine fume hoods (C and I) passed the containment criteria for "as installed (AI)" and "as used (AU)" of $0.1 \mathrm{ppm}$ recommended by ANSI Z 9.5-2003 ${ }^{(19)}$ for hoods set at fully open sash height. Test results also confirm that lower face velocity may not necessarily provide poor containment ${ }^{(1-7)}$ and may be capable of passing the criteria. Local flow structures are more important than the global parameter of the face velocity when considering the overall containment leakage problem.

TABLE III. On-Site Measurement Results

\begin{tabular}{|c|c|c|c|c|}
\hline \multirow[b]{2}{*}{$\begin{array}{l}\text { Fume } \\
\text { Hood }\end{array}$} & \multirow[b]{2}{*}{$\begin{array}{c}\mathbf{V}_{0} \\
(\mathbf{m} / \mathrm{sec})\end{array}$} & \multirow{2}{*}{$\begin{array}{c}\mathrm{C}_{\mathrm{SF6}} \\
\text { Test Mode } \mathbf{A}^{A} \\
(\mathrm{ppm})\end{array}$} & \multicolumn{2}{|c|}{$\mathrm{C}_{\mathrm{SF} 6} \underset{(\mathrm{ppm})}{\text { Test Mode }^{B}}$} \\
\hline & & & $\begin{array}{c}\mathbf{H} / \mathbf{H}_{0}= \\
50 \%\end{array}$ & $\begin{array}{c}\mathbf{H} / \mathbf{H}_{0}= \\
100 \%\end{array}$ \\
\hline A & 0.29 & $>100$ & 48.49 & 62.30 \\
\hline B & 0.32 & $\begin{array}{l}\text { Bottom-middle edge } \\
\qquad>100 \\
\text { Bottom-middle edge }\end{array}$ & 0.06 & 0.39 \\
\hline C & 0.33 & $\begin{array}{c}31.14 \\
\text { Bottom-middle edge }\end{array}$ & 0.02 & 0.03 \\
\hline D & 0.44 & $\begin{array}{c}>100 \\
\text { Bottom-middle edge }\end{array}$ & 2.60 & 1.94 \\
\hline E & 0.44 & $\begin{array}{c}7.36 \\
\text { Bottom-right corner }\end{array}$ & 0.46 & 8.35 \\
\hline $\mathrm{F}$ & 0.45 & $\begin{array}{c}22.20 \\
\text { Bottom-middle edge }\end{array}$ & 0.07 & 2.55 \\
\hline G & 0.46 & $\begin{array}{c}20.89 \\
\text { Bottom-middle edge }\end{array}$ & 0.41 & 0.79 \\
\hline $\mathrm{H}$ & 0.56 & $\begin{array}{c}1.74 \\
\text { Bottom-left corner }\end{array}$ & 0.01 & 0.67 \\
\hline I & 0.76 & $\begin{array}{c}>100 \\
\text { Bottom-middle edge }\end{array}$ & 0.20 & 0.06 \\
\hline
\end{tabular}

${ }^{A}$ Measurements taken at most severe area; point-by-point method used.

${ }^{B}$ ANSI/ASHRAE 110-1995 method used.

\section{CONCLUSIONS AND RECOMMENDATIONS}

$\mathrm{T}$ his study clearly demonstrates the influences of geometric features and the presence of an operator on laboratory fume hood performance by correlating the results obtained from the aerodynamic flow patterns and tracer gas concentration measurements. Complicated turbulent flow patterns, for example, were induced around the bottom edge of the sash, side poles, and doorsill when environmental air drawn by the suction fan of the hood passed over the hood structure and hood operator. The induced flow structures involved the separation of turbulent boundary layers, unsteady motions of shear layers, vortical flows, wake instabilities, and interactions among these characteristic flow structures. These complex flow behaviors can easily contribute to the spread of contaminant leakage and increase the probability of laboratory workers' exposure. The most probable sources for containment leakage of a conventional fume hood are around the doorsill and side poles. Results suggest that a comprehensive strategy based on the entire hood face exposure assessment would reflect a more realistic evaluation of the overall effectiveness of laboratory fume hoods than a methodology based on the single-point, breathing zone sampling.

\section{ACKNOWLEDGMENT}

This research was supported by the Ministry of Education of Taiwan, Republic of China.

\section{REFERENCES}

1. Ivany, R.E., M.W. First, and L.J. Diberardinis: A new method for quantitative, in-use testing of laboratory fume hoods. Am. Ind. Hyg. Assoc. J. 50:275-280 (1989).

2. Fletcher, B., and A.E. Johnson: Containment testing of fume cupboards. I. Methods. Ann. Occup. Hyg. 36:239-252 (1992).

3. Fletcher, B., and A.E. Johnson: Containment testing of fume cupboards. II. Test room measurements. Ann. Occup. Hyg. 36:395-405 (1992).

4. Saunders, T.: Laboratory Fume Hoods, A User's Manual. New York: John Wiley \& Sons, 1993. p. 56.

5. Volin, C.E., R.V. Joao, J.S. Reiman, E. Party, and E.L. Gershey: Fume hood performance: Face velocity variability inconsistent air volume systems. Appl. Occup. Environ. Hyg. 13:656-662 (1998).

6. Maupins, K., and D.T. Hitchings: Reducing employee exposure potential using the ANSI/ASHRAE 110 Method of Testing Performance of Laboratory Fume Hoods as a diagnostic tool. Am. Ind. Hyg. Assoc. J. 59:133-138 (1998).

7. Ekberg, L.E., and J. Melin: Required response time for variable air volume fume hood controller. Ann. Occup. Hyg. 44:143-150 (2000).

8. Durst, F., and J.C. Pereira: Experimental and numerical investigations of the performance of fume cupboards. Build. Environ. 59:153-164 (1991).

9. Durst, F., and J.C. Pereira: Numerical simulation and optimization of the aerodynamics flow field inside fume cupboards. J. Wind Eng. Ind. Aerodynam. 40:127-145 (1992). 
10. Hu, P., D.B. Ingham, and X. Wen: Effect of the location of the exhaust duct, an exterior obstruction and handle on the air flow inside and around a fume cupboard. Ann. Occup. Hyg. 40:127-144 (1996).

11. Hu, P., D.B. Ingham, and X. Wen: Effect of baffles and a louvered bypass on the airflow and the convective patterns of contaminant inside a fume hood. Am. Ind. Hyg. Assoc. J. 59:303-312 (1998).

12. Nicholson, G.P., R.P. Clark, and M.L. De Calcina-Goff: Computational fluid dynamics as a method for assessing fume cupboard performance. Ann. Occup. Hyg. 44:203-217 (2000).

13. Lan, N.S., and S. Viswanathan: Numerical simulation of airflow around a variable volume/constant face velocity fume cupboard. Am. Ind. Hyg. Assoc. J. 62:303-312 (2001).

14. Kirkpatrick, A.T., and R. Reither: Numerical simulation of laboratory fume hood airflow performance. Trans. ASHRAE Career and Technical Education 104:999-1011 (1998).
15. American Society of Heating, Refrigeration and Air Conditioning Engineers, Inc. (ASHRAE): Method of Testing Performance of Laboratory Fume Hoods. (ANSI/ASHRAE Standard 110-1995). Atlanta, Ga.: ASHRAE, 1995.

16. Tennekes, H., and J.L. Lumley: $A$ First Course in Turbulence. Cambridge, Mass.: The MIT Press, 1972. pp. 223247.

17. Kim, T., and M.R. Flynn: The effect of contaminant source momentum on a worker's breathing zone concentration in a uniform freestream. Am. Ind. Hyg. Assoc. J. 53:757-766 (1992).

18. Flynn, M.R., and B. Ljungqvist: A review of wake effects on worker exposure. Ann. Occup. Hyg. 39:211-221 (1995).

19. American National Standards Institute, Inc. (ANSI): Laboratory Ventilation (ANSI/AIHA Z9.5-2003). [Standard] New York: ANSI, 2003. 